\title{
EFEITOS BUCAIS DA RADIOTERAPIA NO TRATAMENTO DO CÂNCER DE LARINGE
}

\author{
Juliana Beatriz ONGARATTO; Francine Baldin ABLE; Marcela Lima Cardoso SELOW
}

O câncer de laringe é um dos mais freqüentes a atingir a região de cabeça e pescoço, representando cerca de $25 \%$ dos tumores malignos desta área (DIAS et al, 2001). O tabaco é considerado o fator etiológico mais importante, sendo o risco 14,3 vezes maior em fumantes (DIAS et al, 2001). As principais formas de tratamento para o câncer de laringe são a laringectomia e a radioterapia que exibe complicações bucais importantes. $O$ objetivo deste trabalho é discutir os efeitos bucais provocados por este tratamento. A radioterapia tem como princípio uma ação local que depende da diferença da radiossensibilidade entre tumor e tecidos normais (FAUCl et al, 1998). Os efeitos colaterais agudos provocados pela radioterapia que acometem a cavidade bucal incluem: mucosite, digeusia, disfagia, infecções oportunistas; e os efeitos tardios que podem ocorrer são: trismo, osteorradionecrose e cárie de radiação. A hiposalivação trata-se de um efeito crônico de suma importância, uma vez que contribui para o desenvolvimento de outras manifestações bucais, como a cárie e ardência bucal. O paciente em tratamento radioterápico deve ser acompanhado por uma equipe multidisciplinar, em função da radioterapia não acarretar somente efeitos biológicos, mas também psicológicos. 